\title{
EXPERIENCIAS INNOVADORAS E INTEGRADORAS DE JUSTICIA RESTAURATIVA EN EJECUCIÓN DE CONDENA: PROYECTO RESTAURAVIDAS. REINTEGRACIÓN EN EL PAÍS DE ORIGEN
}

\author{
Francisca Lozano Espina \\ Doctoranda de Psicología Social en la Universidad Nacional de \\ Educación a Distancia \\ Prof. Colaboradora en la Universidad Francisco de Vitoria. \\ Itziar Fernández Sedano \\ Prof. Titular, Dpto. Psicología Social y de las Organizaciones, \\ Universidad Nacional de Educación a Distancia \\ Title: Novel Restorative justice experiences during the serving of sentences: the \\ "Restauravidas» Project. Reintegration in the country of origin.
}

Resumen: La presente publicación sintetiza un estudio basado en datos descriptivos provenientes del desarrollo de un programa de intervención con personas españolas condenadas a privación de libertad en el extranjero por el tráfico de drogas. El doble objetivo de este trabajo radica en el análisis de determinados procesos psicológicos, criminológicos y restaurativos presentes en estas personas en su proceso de reintegración tras la experiencia traumática, así como la detección del perfil mayoritario en este tipo de delitos, para la aplicación de este conocimiento de cara a futuras políticas y acciones sensibilizadoras y preventivas.

Palabras clave: Prisión; Extranjero; Perfil delictivo; Trauma; Resiliencia; Revinculación familiar; Justicia restaurativa; Responsabilización; Reparación; Reinserción.

Abstract: This publication summarizes a study based on descriptive data from the development of an intervention program with Spanish people sentenced to deprivation of liberty abroad for drug trafficking. The dual goal 
of this work lies in the analysis of certain psychological, criminological and restorative processes present in these people in their reintegration process after the traumatic experience, as well as the detection of the majority profile in this type of crime, for the application of this knowledge for future sensitizer and preventive policies and actions.

Keywords: Prison; Foreigner; Criminal profile; Trauma; Resilience; Family Reengagement; Restorative Justice; Accountability; Reparation; Reintegration.

Sumario: 1. Introducción. - 2. Programa Restauravidas. Reintegración en el País de Origen. - 2.1. Justificación del programa. - 2.2. Conceptualización del programa. - 2.3. Objetivos. - 2.4. Evolución de Restauravidas. - 3. La justicia restaurativa en Restauravidas. - 4. Análisis de casos. - 4.1. Metodología. - 4.2. Perfil delictivo. - 4.3. Elementos psicosociales y criminológicos para la reintegración de los reclusos que retornan a su país de origen. - 4.3.1. Resiliencia. - 4.3.2. Experiencia transformativa. - 4.3.3. Responsabilización. - 4.3.4 Bienestar emocional. - 4.3.5. Revinculación familiar y reparación. - 5. Conclusiones. - 6. Bibliografía.

\section{Introducción}

La vulnerabilidad de las personas en prisión, sus carencias y necesidades desatendidas es un tema controvertido que ha suscitado el interés de numerosos autores (Cabrera y Ríos, 1998; Cid, 2005; Garrido, 1982). Teniendo en cuenta el Informe del Ministerio del Interior (2017), el impacto de la vida en prisión no es el mismo para todos los reclusos. Así, hay una serie de indicadores que condicionan los efectos de la vida en prisión. Estos pueden clasificarse en los que guardan relación con el carácter penal y los de índole personal/social. Dentro de los primeros se encuentran el número de ingresos, la frecuencia y el tiempo de cada estancia en prisión, las características de los centros, la situación penitenciaria, así como el nivel de participación en actividades y programas. Entre los factores personales y sociales más importantes destacan la situación familiar y laboral, la edad, los antecedentes mentales, el estado de salud y la personalidad. En particular, el apoyo social externo de la familia y amigos es uno de los elementos que tiene una relevancia fundamental para el día a día en la cárcel.

Además, existen determinadas características de las personas privadas de libertad que pudieran venir acompañadas de situaciones que dificultan su estancia en prisión, al generar una serie de necesidades que difícilmente son atendidas en prisión, ante la inexistencia de recursos específicos. Así, podemos hablar de enfermedad mental, personas mayores, población transexual, adicciones, etc.

No obstante, pocas veces se pone el foco en otro perfil poblacional presente en el sistema penitenciario español. Nos referimos a los españoles que retornan a las cárceles de su país tras haber iniciado su condena (y en 
ocasiones concluido) en prisiones extranjeras, donde la miseria vivida llega a un nivel extremo, junto con otra serie de circunstancias que agravan la situación, tal como la soledad, la enfermedad no tratada o la xenofobia.

En el estudio que presentamos, se analiza la situación de reclusos de nacionalidad española en prisiones extranjeras, principalmente América Latina, como destino mayoritario, los cuales retornan a su país de origen, tras vivir bajo condiciones físicas y sociales que intensifican su malestar.

El sistema penitenciario, así como el trato general a las personas recluidas en prisión, se ve expuesto con frecuencia, tanto en muchos países de América Latina como de otras regiones del mundo, a la falta de cubrimiento suficiente de necesidades básicas, a la escasez de recursos para llevar a cabo las actividades de reinserción social, como en Guatemala (Leal y García, 2008) o Colombia (Ruiz, 2014), y a la poca capacitación del personal de custodia y del equipo profesional (Concha, 2007). Ello no implica la existencia en las prisiones de Iberoamérica de programas exitosos y positivos (Bravo, 2011), tal que el proyecto actual puesto en marcha en Brasil entre el Departamento Penitenciario Nacional brasileño y el Programa de las Naciones Unidas para el Desarrollo, que comparten el objetivo común de acercar e insertar los mecanismos de justicia restaurativa en las cárceles del país ${ }^{1}$, o bien la Red Latinoamericana de Educación en Contextos de Encierro -RedLECE, cuyo objetivo consiste en promocionar la cohesión social de las sociedades latinoamericanas a través de sus políticas públicas de educación, salud, administración de la justicia, fiscalidad y empleo (Rangel, 2009).

El Programa Restauravidas. Reintegración en el País de Origen, iniciativa de la Fundación Abogacía Española, nace como primera idea germinal a finales de 2018, materializándose el 4 de octubre de 2019, y lo hace con la vocación de acompañar a estas personas en su proceso de «reconstrucción» y de adaptación, tratando de cubrir una serie de necesidades detectadas, que tienen que ver con la elaboración del trauma y el reencuentro familiar, la información y asesoramiento jurídicos, la reflexión sobre la responsabilidad por la decisión consciente de participar en el delito, y la reinserción social, con miras a la consecución final de la libertad y el retorno a la comunidad de origen. Estas necesidades componen los cuatro ejes sobre los que se asienta esta iniciativa: el eje psicológico, el jurídico, el restaurativo y el reinsertador.

1 Este proyecto que comienza en forma de piloto en el estado brasileño de Rio Grande do Sul, se encuentra actualmente en proceso de implementación, dotado de acciones de formación, capacitación y ejecución (conocimiento a través de participación directa de la autora en las acciones de formación y capacitación de los profesionales seleccionados para su ejecución). 
Se trata de un programa pionero en nuestro país, a la vez que innovador, al poner el foco en esta población minoritaria y desatendida hasta el momento en sus necesidades específicas, fruto de su situación excepcional, como también por el hecho de integrar el trabajo en los cuatro ejes complementarios.

Veintitrés personas, tres de ellas mujeres (13\%), y veinte hombres $(87 \%)^{2}$, son los beneficiarios que han participado en esta experiencia hasta el momento actual, número que se ha visto afectado por la situación de pandemia acaecida durante parte del tiempo de desarrollo del programa y que, a pesar de no haber frenado su actividad de manera total, sí ha generado un viraje en la misma.

\section{Programa Restauravidas. Reintegración en el País de Origen}

\subsection{Justificación del programa}

Los participantes de este estudio inician su condena en lugares alejados de su patria y lo hacen con un sueño que se convierte en necesidad en muchos de los casos: retornar a su país de origen y poder concluir el cumplimiento de su condena aquí, cerca de familiares y otros significativos, apoyos necesarios para pasar la dura prueba de vivir privado de libertad (Informe del Ministerio del Interior, 2017), y también verse rodeados de personas con las que sentirse conectados en un espacio caracterizado principalmente por la incomunicación y las restricciones.

Muchas de estas personas han experimentado en el extranjero una elevada experiencia de indefensión, asociada al desconocimiento del funcionamiento penitenciario en sus centros de cumplimiento, junto con el afrontamiento de códigos conductuales, actitudinales y morales diferentes, y la incomprensión del idioma en algunos casos, los menos (las estadísticas arrojadas en esta investigación hablan mayoritariamente de la Latinoamérica castellano-parlante 3 ). Carentes además del suficiente asesoramiento profesional adaptado a sus necesidades, a pesar del apoyo facilitado por los Consulados en el país en cuestión. A esta situación dura y difícil de

2 Según los últimos datos disponibles facilitados por la propia Secretaría General de Instituciones Penitencias, a 25 de septiembre de 2020, la población penitenciaria española presenta una distribución por sexos del $92,72 \%$ en el caso de los hombres, y del 7,28\% en el caso de las mujeres, estadística que dista ligeramente de la distribución por sexos de la población participante en Restauravidas.

3 De las 23 personas que han participado en el programa de intervención Restauravidas hasta el momento de publicación del presente artículo, sólo 4 han procedido de países en los que la lengua oficial no era el castellano, que son: Francia, Malta y Brasil, país del que procedían 2 personas. 
superar, se añade la soledad, añoranza y tristeza por la falta de un sustento emocional accesible y cercano que puede brindar la red de apoyo social a los reclusos que se encuentran en su contexto cultural.

A lo largo de los últimos años, esta situación ha sido vivida por cerca de un millar de españoles cada año. Según datos facilitados por la Fundación Abogacía Española ${ }^{4}$, en 2020 (datos del mes de diciembre) 862 españoles iniciaron su condena en el extranjero, 950 en enero de 2019, y 972 en julio de $2018^{5}$.

Existe un nexo de unión entre la gran mayoría de estas personas, que es el relato de tratos que vulneran los derechos humanos más básicos y que les llevaron a vivir experiencias de gravísimas carencias, abusos, riesgo para sus vidas e indignidad. La suma de todas estas experiencias puede llegar a un nivel importante de trauma, con las posibles consecuencias a nivel psicológico (Davidson y Foa, 1991; Echeburúa, Amor y Corral, 2005; Páez, Vázquez y Echeburúa, 2013; Tennant, 2006).

La llegada al país de origen no viene exenta de retos: la adaptación a un nuevo contexto penitenciario, quizá desconocido anteriormente, si es que se trata de su primera condena privativa de libertad ${ }^{6}$. El choque entre expectativas y realidad es frecuentemente una experiencia subjetiva de difícil manejo si es que este balance se salda con la decepción, percepción de falta de control, indefensión, y otra serie de vivencias psicológicas asociadas a su vida penitenciaria. Además, es altamente probable que el reencuentro con la familia que le ha estado esperando y luchando por su retorno, suponga una nueva fuente de estrés y sufrimiento, dados los sentimientos generados por el delito cometido, la detención, condena, y todas las consecuencias de esta situación. Todo ello hace que esta readaptación, aparentemente bajo condiciones ostensiblemente mejoradas, no sea tan sencilla y fluida como fuera de esperar. También es posible que deban enfrentarse incluso al rechazo familiar.

Muchas veces el contacto durante el tiempo de condena no es sencillo, pero no mejora necesariamente a la salida de esta persona de prisión (Visher y O’Connell, 2012), ya que la restructuración familiar acaecida

${ }^{4}$ Datos obtenidos de la Dirección General de españoles en el Exterior y Asuntos Consulares a través del Informe anual de Apoyo a las personas españolas presas en el extranjero de diciembre de 2020 realizado por la Fundación Abogacía, documento no publicado.

5 Datos más precisos acerca de los lugares de procedencia de estas personas, y otras características, pueden ser encontradas en el artículo de Esther Pascual, titulado «La incidencia de la justicia restaurativa en la ejecución de la pena con personas condenadas por tribunales extranjeros trasladadas a España para cumplir su condena» (véase en este mismo número 26, Pascual).

${ }_{6} \mathrm{El} \mathrm{73,9 \%}$ de los 23 participantes en Restauravidas son delincuentes primarios, lo que significa que esta es su primera condena. Datos relativos a este aspecto serán presentados más adelante, puestos en relación con los 21 participantes elegidos para el desarrollo de la investigación. 
tras la ausencia durante la condena puede generar resistencias para volver a incluir a este miembro nuevamente en el sistema familiar a la hora de cumplir el rol y funciones que «le pertenecían» con anterioridad a la detención y que han sido asumidos de necesidad por otro miembro, el cual ocupa en el momento actual una posición de poder. Estas personas y sus familiares necesitan ayuda para afrontar estos cambios y dificultades; la mayoría se encuentran confundidos y desorientados. Incluso pueden sentirse extraños, desconocidos entre sí.

El Programa Restauravidas pretende ayudar en la reestructuración de toda esta emocionalidad personal y familiar, tanto en relación a la elaboración del trauma, como en el proceso de revinculación, acompañando a cada persona en estos procesos de readaptación, y de acercamiento a los seres significativos de su entorno más íntimo.

Además, estos individuos aumentan su incertidumbre y su percepción de no control al carecer de información acerca del funcionamiento del sistema penitenciario español, quizá porque no han tenido contacto previo con el mismo, quizá por su evolución y cambio tras tantos años fuera, si es que ya habían sufrido condenas anteriores. El asesoramiento jurídico ofrecido les ayuda a situarse en el contexto penitenciario en el que se encuentran, conociendo el sistema de recursos que pueden interponer contra las resoluciones de la administración penitenciaria y cómo y cuándo interponerlos. Les permite despejar dudas procesales y conocer los recursos a los que pedir ayuda (como por ejemplo el Servicio de Orientación y Asistencia Jurídico-Penitenciaria -SOAJP-).

De manera adicional, el presente programa se enmarca dentro de la justicia restaurativa al girar sobre sus tres ejes principales: por un lado, la justicia restaurativa parte de la responsabilización y reintegración del victimario, imprescindible para que pueda tener lugar un proceso restaurativo $^{7}$, así como reflexionar acerca del impacto de su delito en un nivel macro $^{8}$. Por otro lado, el propósito prioritario consiste en la reparación de la víctima, la cual ha sido dañada por el delito; en este caso se trata de la familia de la persona condenada, dado que han cumplido una pena emocional de alta intensidad por la condena y sus consecuencias. Por

7 La debida y necesaria reestructuración familiar tras la marcha de un miembro con funciones importantes (Minuchin y Fishman, 1984), sacar adelante a los hijos e hijas en soledad, trabajar sin descanso para llegar a fin de mes y pagar a los abogados para la defensa del familiar encarcelado, los gastos para las visitas a prisión del ser querido, el acompañamiento en procesos de muerte o de crecimiento, etc.

8 La asunción del hecho delictivo y el proceso de responsabilización son difíciles cuando no existe una víctima directa, o unipersonal, y la persona encuentra fácil el amparase en que «lo habría hecho otro si no lo hubiera hecho yo». Asumir que su decisión supone participar de un complejo y mastodóntico engranaje delictivo que se cobra vidas y genera adicciones y sufrimiento es un proceso laborioso, facilitado cuando es acompañado y confrontado por profesionales de la justicia restaurativa. 
último, busca la pacificación social y la integración de la comunidad en estos procesos, dado que este individuo debe retornar a la comunidad en algún momento, y pueda hacerlo desde la confianza en el sistema en el que debe reintegrarse.

Todos estos enfoques de trabajo facilitan la reinserción social y comunitaria, siendo que en este acompañamiento son atendidas también necesidades específicas, relacionadas con tal reinserción.

\subsection{Conceptualización del programa}

Desde estos planteamientos surge el Programa Restauravidas. Reintegración en el País de Origen. Parte del propósito de acompañar a estas personas, facilitando el proceso de sanación tras la experiencia traumática relatada, y la integración en su historia de dicha experiencia, así como la adaptación a su nueva vida una vez ha retornado del encierro en el extranjero, e igualmente la reflexión necesaria acerca de su participación en la maquinaria delictiva, posiblemente de gran escala, trabajo que se ha demostrado difícil y escurridizo, al haber vivido la experiencia desde la percepción de no control y el sufrimiento de quien se considera a sí misma víctima de su propio delito.

La iniciativa para el mismo nace de la Fundación Abogacía Española, institución que se ocupa, entre otras funciones, de velar por los derechos y necesidades de las personas españolas que se encuentran cumpliendo condena en el extranjero, en particular, en relación a su acceso a la justicia, tratando de aportar una defensa de calidad, como a su situación personal de especial vulnerabilidad, dadas las circunstancias. El conocimiento de estas necesidades surge de la atención allí, en los países de cumplimiento de condena, y es detectada la necesidad de ampliar la atención también a su regreso al país de origen, España. Este regreso es facilitado por la Fundación en colaboración con otros organismos como FRONTEX (Agencia Europea de la Guardia de Fronteras y Costas), los diferentes consulados y embajadas, etc. Una vez aquí, no terminan las dificultades y necesidades, sino que mutan a otras diferentes, una vez asegurados los derechos mínimos.

El programa está concebido para ser desarrollado por dos profesionales, ambas procedentes de la justicia restaurativa, con profesiones complementarias y necesarias para dar respuesta a los objetivos de Restauravidas: derecho y psicología.

La actividad es desarrollada de manera inicial en el Centro Penitenciario de Madrid V, Soto del Real, primer centro de cumplimiento de estas personas que retornan al país, previo a su traslado a otros centros más próximos a su lugar de arraigo, donde concluirán su condena. Es durante este compás de espera cuando tiene lugar el desarrollo del programa, sin solapar la atención con la asistencia ofrecida por los SOAJPS 
ni con los equipos de tratamiento del propio centro penitenciario (ámbitos jurídico y psicológico respectivamente).

Esta experiencia pionera y única recibe desde el principio una buena acogida por parte de la Secretaría General de Instituciones Penitenciarias, también por parte del propio Centro Penitenciario, cuyos responsables pasan a ser colaboradores necesarios desde un primer momento, e igualmente por parte de las personas penadas, beneficiarias del mismo, las cuales transmiten su agradecimiento y satisfacción, a la vez que cumplen un efecto divulgativo dentro del propio centro penitenciario.

Los objetivos de Restauravidas pretenden cubrir esas necesidades detectadas, desde un planteamiento integrador de las mismas, que son trabajadas de manera longitudinal, a lo largo de todas las sesiones que componen el programa.

\subsection{Objetivos}

Objetivo general:

- Acompañar a las personas en su llegada a su país de origen tras el encierro en el extranjero, intentando cubrir sus necesidades de adaptación.

Objetivos específicos:

- Favorecer el proceso de sanación de la experiencia traumática, integrando dicha experiencia en su propia historia.

- Aumentar la percepción de control de su vida en prisión a través del manejo de información relevante para su vida penitenciaria.

- Generar red de apoyo en prisión durante su estancia en el centro penitenciario.

- Facilitar procesos de responsabilización por el daño causado por el delito; interiorización del impacto y de su papel en el mismo como mecanismo de evitación de la reincidencia.

- Ayudar a la adaptación a la vida de vuelta a su país, en un ámbito personal.

- Preparar a las personas para la reincorporación a la vida familiar.

- Promover procesos de reparación y restauración de las relaciones familiares dañadas por el delito y la condena.

- Asesorar y acompañar en la salida en libertad en diversos ámbitos de funcionamiento. 


\subsection{Evolución de Restauravidas}

El inicio de la puesta en marcha de Restauravidas, supone un continuo proceso de adaptación y flexibilización de los contenidos del mismo, al tratarse de un programa vivo y cambiante en el que las personas participantes siguen su propio flujo de entrada y salida según una serie de circunstancias penitenciarias ${ }^{9}$.

El funcionamiento del programa está basado en la metodología de los círculos de diálogo, práctica habitual en el contexto de la justicia restaurativa. Esta dinámica permite que todos los asistentes, sentados en disposición circular compartan un espacio de igualdad, respeto y seguridad. Según Kay Pranis (2010, pág.28) «en el círculo la sabiduría surge a partir de las historias personales»; esta sabiduría colectiva es suficiente y hace innecesario el entrenamiento de los participantes para que fluya la verdad más íntima de cada individuo.

A pesar de que en la conceptualización inicial era contemplada la posibilidad de resistencias a exponer abierta y grupalmente dentro del círculo el relato de la experiencia traumática, la realidad muestra un sano y catártico proceso en el que se suceden relatos complementarios, diferenciados casi exclusivamente por el lugar desde el que esas experiencias son vividas y el grado de miseria, carencias y sufrimiento que cada persona ha debido experimentar (miedo, soledad, consecuencias físicas de las privaciones, vejaciones y situaciones de la mayor indignidad que han debido afrontar). Estas personas, una vez llegadas a España, se ven sometidas a multitud de circunstancias cambiantes: por un lado viven la cárcel española como un espacio de privilegios y derechos que les han sido restringidos en el extranjero (comida, cama, espacio vital mínimo, seguridad ataques de otros compañeros-), y se están adaptando a ellos; también a volver a recuperar la idea de que son seres de derechos, que merecen ser tratados con dignidad, respeto, y que es el deber de la institución cubrir sus necesidades más básicas durante su encarcelamiento.

El efecto terapéutico de contar en alto las vivencias, especialmente si se trata de experiencias traumáticas (Asnaani, McLean y Foa, 2016), es presenciado en este espacio; incluso aquellas personas resistentes a compartir en un principio participan de la dinámica y permiten que el programa pueda fluir dentro del círculo, sin necesidad de trasladar el trabajo de los aspectos más delicados al formato individual.

El programa se desarrolla siguiendo una frecuencia semanal, desde octubre de 2019 hasta el inicio de las medidas de estado de alarma ${ }^{10}$, que

9 Traslados al centro de cumplimiento definitivo, progresiones de grado o nuevas incorporaciones.

10 En marzo de 2020 la población española (así como la población mundial) quedó confinada debido a la pandemia provocada por el coronavirus SARS-CoV-2, hecho que 
provocaron una interrupción de la actividad hasta septiembre de 2020, momento en el que, a pesar de permanecer el Centro Penitenciario aún cerrado a actividad externa, Restauravidas «muta» y pasa a convertirse en Restauravidas en la nube. La Fundación Abogacía Española decide dar continuidad al mismo a través de las nuevas tecnologías, una vez se da la circunstancia de que regresan a España, desde Perú, un número de compatriotas con la totalidad de su condena cumplida. El programa adopta una nueva naturaleza la cual, a pesar de cierta prevención inicial al respecto, sigue conservando sus cualidades de espacio terapéutico, restaurativo y reinsertador ${ }^{11}$.

\section{La justicia restaurativa en Restauravidas}

Resulta pertinente la exposición de los principios más importantes de la justicia restaurativa, dado que ofrece un marco conceptual y filosófico a Restauravidas, al nutrirse de sus principios y valores.

La justicia restaurativa puede ser considerada una disciplina joven, dado que surgió en el mundo académico en la década de los setenta, a pesar de que su práctica social tiene arcaicos antecedentes (Larson y Zehr, 2007; Olalde, 2015). Desde estos inicios ha generado un amplio interés y por tanto un considerable volumen de investigación desde las diversas disciplinas próximas a la justicia restaurativa, como el derecho, la criminología, la psicología y el trabajo social principalmente, con el propósito de aportar conocimiento acerca de los mecanismos de funcionamiento de la justicia restaurativa y de los diferentes factores implicados en la misma.

El concepto de justicia restaurativa como práctica jurídico-criminal surge por primera vez en la ciudad canadiense de Elmira en 1974, según Larson y Zehr (2007). De esta primera experiencia restaurativa comienzan a desarrollarse diferentes programas de mediación penal (VOM -Victim Ofender Mediation-) en Canadá y Estados Unidos, precediendo el surgimiento de este tipo de iniciativas a nivel internacional, y provocando un significativo cambio en el enfoque de los asuntos penales en diferentes países.

No obstante estos inicios documentados, son muchos los autores que señalan que los orígenes de la justicia restaurativa se hallan en diferentes

paralizó toda actividad que no fuese considerada de primera necesidad.

11 Se hace necesaria adaptar la duración del mismo y Restauravidas pasa a estar conformado por 5 sesiones en esta modalidad, a diferencia de las 10 sesiones del programa original. En estas 5 sesiones es condensado el trabajo en su totalidad, facilitado por el vínculo previo de las personas que participan en el mismo, al proceder del mismo lugar donde han cumplido su condena y se han acompañado en la experiencia de encierro. 
prácticas tribales y aborígenes desconectadas entre sí, al ubicarse en diferentes lugares del mundo, como tribus maoríes en Nueva Zelanda, ciertas tribus nativas en Estados Unidos, consejos tribales en África, tribus aborígenes o Primeras Naciones de Canadá (De Mesmaecker, 2011; Gustafson, 2018; Maglione, 2017; Umbreit, Vos, Coates y Lightfoot, 2005).

Ya desde la aparición de este paradigma, se produce un volumen destacable de discusión entre profesionales desde diferentes sectores, siendo que algunos de estos académicos u operadores jurídicos entendían justicia restaurativa y retributiva como polos contrapuestos, véase Howard Zehr en su obra Changing Lenses: a New Focus for Crime and Justice (1990). Otros autores han cuestionado este planteamiento adversarial entre ambos paradigmas, al entender que la justicia restaurativa no puede sustituir a la justicia tradicional, al necesitar la primera de ciertos condicionantes para que pueda ser llevada a cabo, como la responsabilización de la persona ofensora y el deseo de verse reparada a través del encuentro, por parte de la persona víctima. Llegado cierto punto, es el propio Zehr (2007) quien evoluciona en su planteamiento inicial, y llega a entender la justicia como un continuo donde también la retribución juega un rol destacado y necesario en ocasiones. Igualmente otras investigaciones cuestionan la necesidad del castigo en la percepción de justicia tras la trasgresión de la norma (Okimoto, 2009).

Al tratarse de un paradigma joven, también la definición del mismo ha generado diversas propuestas, siendo la aportada aquí en España por Ríos, Pascual, Segovia, Etxebarria y Lozano (2016, pág. 32), la que proponemos aquí: «la filosofía y el método de resolver los conflictos que atienden prioritariamente a la protección de la víctima y al restablecimiento de la paz social, mediante el diálogo comunitario y el encuentro personal entre los directamente afectados, con el objeto de satisfacer de modo efectivo las necesidades puestas de manifiesto por los mismos, devolviéndoles una parte significativa de la disponibilidad sobre el proceso y sus eventuales soluciones, procurando la responsabilización del infractor y la reparación de las heridas personales y sociales provocadas por el delito».

En cuanto a los valores a los que la justicia restaurativa se adscribe, y que Restauravidas hace suyos también, presentamos los propuestos por Chapman, Van Hoek y Wolthuis en 2018, que son: relación, justicia, respeto, responsabilidad y verdad, añadiendo que los elementos clave en los procesos restaurativos son la inclusión, la aceptación libre y voluntaria, la participación, el diálogo, entendimiento mutuo, la acción consensuada y los compromisos mantenidos.

Todas las conceptualizaciones del paradigma incluyen los tres ejes sobre los que descansa la justicia restaurativa, ya señalados: responsabilización, reparación y corresponsabilización del tejido social; igualmente la premisa de que el delito no es sólo una trasgresión de la ley, lo normativo, 
sino que fundamentalmente se trata de un daño, un agravio que vulnera los derechos y necesidades de las personas y sus relaciones.

Desde la criminología y el derecho, existen mayoritariamente enfoques dirigidos a la víctima (Victim-friendly options), dado que la atención a la misma, su reparación por el daño sufrido son prioridades desde este paradigma (Wemmers, 2019). También hay enfoques que se centran en el victimario, defendiendo, por ejemplo, que la participación en procesos restaurativos suponen un potente elemento de reinserción y de no reincidencia (Sherman, Strang, Mayo-Wilson y Barak, 2015).

Esta investigación pretende poner el foco en un perfil especial de persona victimaria: aquella que ha cometido un delito contra la salud pública y que ha sido detenida y condenada fuera de las fronteras de su país de origen y residencia. Esta circunstancia excepcional le ha llevado a vivir una experiencia de condena cualitativamente diferente de la que habría experimentado de haber sido condenado en España. A continuación, procederemos y presentar un análisis de casos, que arroja la elaboración de un perfil delictivo predominante que ofrece claves para futuras líneas de actuación con fines sensibilizadores y preventivos frente a este tipo de delitos.

\section{Análisis de casos}

La investigación que presentamos está enmarcada dentro del Proyecto Restauravidas. Reincorporación al País de Origen, como una parte del mismo. De las 23 personas participantes hasta la actualidad en el programa de intervención ${ }^{12}, 21$ de ellas son condenadas por delitos contra la salud pública, mientras que otras 2 reciben condenas por delitos diferentes que no guardan relación. Es con estas 21 personas que cuentan con tal característica común sobre las que va a realizarse la presente investigación, a través del análisis de casos, con el propósito de generar perfiles y encontrar claves útiles a considerar en potenciales políticas de prevención.

\subsection{Metodología}

Siguiendo el Modelo Investigación-Acción propuesto por el psicólogo social Kurt Lewin (1988), hemos tratado de vincular el programa de intervención (jurídico, psicológico, restaurativo y reinsertador) con el planteamiento experimental propio de las ciencias sociales.

12 Todas han aceptado su participación de manera voluntaria, a pesar de haber sido derivados por el centro penitenciario. Se ha solicitado además su consentimiento informado. 
Una vez detectada la necesidad de acción con las personas que regresan a España tras condenas iniciadas en el extranjero, es diseñado un programa interventivo de ayuda y acompañamiento en los ámbitos señalados. A la par, y siguiendo con el modelo lewiniano, son formuladas y seleccionadas las hipótesis sobre las que es desarrollada la investigación, con el propósito de aportar conocimiento nuevo, partiendo de la realidad, y apoyado en el método científico, conocimiento que pueda proporcionar nuevas claves para generar cambio social.

Dada esta metodología de investigación-acción, surge el proyecto de investigación, el cual presentamos a continuación, basado en el programa de intervención Restauravidas. Los datos descriptivos que dicho programa aporta, y que serán presentados a continuación, proceden de cuatro fuentes diferentes y complementarias, que son:

- La extrapolación de los mismos a partir de entrevistas semiestructuradas, creadas exprofeso para el proyecto de intervención e investigación, y que son empleadas como herramienta de evaluación al principio y al final de la participación en el programa.

- Los registros provenientes de la observación participante de las profesionales, las cuales asumen este rol de manera alternativa, según quién facilite la sesión en cada momento.

- Las propias manifestaciones expresivas espontáneas de los participantes, las cuales también son registradas por las profesionales.

- Las respuestas directas a las preguntas de las profesionales, igualmente registradas de manera escrita.

Todos estos datos son recabados por las profesionales que desarrollan su labor de orientación e intervención, a la par que científica.

\subsection{Perfil delictivo}

A través de la información obtenida sobre las personas participantes en este estudio, es detectado un perfil delictivo prevalente, en relación a los siguientes aspectos:

- Género: el 90\% ( $\mathrm{n}=19)$ de las personas participantes en la investigación pertenecen al género masculino, mientras que el $10 \%$ restante $(\mathrm{n}=2)$ son mujeres.

- Edad: la media de edad en la que se encuentran los participantes es de 47 años, siendo el rango de edad de mayor presencia, el existente entre 46 y 55 años $(52 \%, \mathrm{n}=11)$.

- Primariedad delictiva: el $71 \%(\mathrm{n}=15)$ de las personas condenadas en el extranjero y participantes en Restauravidas cometen un delito 
por primera vez, frente al 29\% (n=6) que ya había delinquido y habían sido condenado anteriormente.

- Motivo para delinquir: el 71\% ( $\mathrm{n}=15)$ presentan una apremiante necesidad económica, siendo que incluso 2 de estas personas se hallan en situación de calle, circunstancia de especial vulnerabilidad para la captación. El 14,5\% (n=3) se dedicaban al tráfico de droga, a través de una infraestructura de mayor o menor escala, creada para la venta de droga. El 14,5\% restante $(n=3)$ delinquen debido a motivo mixto, esto es, tráfico como medio de subsistencia, sin enriquecimiento, junto con situación de necesidad económica.

- Circunstancias de la detención: el 52\% $(\mathrm{n}=11)$ de los integrantes del estudio han sido utilizados como cebos por parte de las mafias de tráfico, es decir, fueron detenidos mientras otra carga de droga de mayor importancia pasaba los controles gracias a la distracción generada por la detención de esta persona. El 48\% (n=10) no sufrió esta circunstancia.

- Tiempo de estancia en la cárcel extranjera: estas personas han permanecido una media de 4 años y 1 mes cumpliendo condena en el extranjero, media especialmente distorsionada por la existencia de dos casos, en los que esta estancia en el extranjero ha sido significativamente elevada, tratándose de 14 y 10 años con 3 meses en cada uno de estos casos.

- Contemplación previa de las consecuencias subsiguientes: únicamente el 29\% de las personas que han participado en este estudio reflexionaron previamente, aunque fuese de manera mínima, acerca de la posibilidad de ser detenidos y de lo que tal detención pudiera suponer en sus vidas. El 71\% restante reconocen no haber pensado sobre esta opción, o bien haber desechado estos pensamientos, como forma para poder seguir adelante con el plan que conlleva un peligro.

De los datos presentados es posible establecer un perfil delictivo, el cual nos puede alertar acerca de las personas más vulnerables de cara a la comisión de este tipo de delito. Se trata de un varón, entre 46 y 55 años, que delinque por primera vez, motivado por la necesidad económica y que no repara en las posibles consecuencias que este delito pueda generar a nivel personal ${ }^{13}$.

El dato relativo a las circunstancias de la detención (ser utilizado como cebo) representa al $52 \%$ de la muestra. Aun siendo algo más de la mitad de la misma, no podemos decir que se trate de un hecho

${ }_{13}$ Un análisis más profundo de la relación entre estas variables es presentado por Esther Pascual, publicado en este mismo número de la revista. 
mayoritario, aunque sí de una frecuencia suficiente como ser tenido en consideración.

En cuanto a la contemplación previa de las consecuencias subsiguientes, se trata de un dato de especial relevancia que no debiera ser descuidado, principalmente porque el mecanismo psicológico subyacente, la evitación cognitiva del posible desenlace y sus graves consecuencias, permite que las personas consideren esta opción delictiva como viable y aceptable en sus vidas, incluso en los casos en que han podido reflexionar mínimamente sobre ello y no obstante, descartar esta posibilidad, dado lo molesto de estos pensamientos, una vez es tomada la decisión de convertirse en «mula».

Curiosamente, todas las personas que reconocen haber dedicado un mínimo pensamiento a esta posibilidad y admiten haber desechado tales pensamientos, coinciden con las personas que anteriormente habían cometido un delito y habían sufrido las consecuencias del mismo. Es decir, sólo aquellos individuos que no son delincuentes primarios admiten un mecanismo psicológico de minimización de riesgos, o bien de confianza en las propias capacidades para salir exitoso de la situación ya conocida, mecanismo que ha favorecido su participación en un delito sumamente riesgoso, con graves consecuencias, que les ha llevado al «infierno» vivido. Por tanto, la ilusión de invulnerabilidad motivada por la evitación cognitiva resulta más característica entre aquellos que no tienen antecedentes delictivos.

Los mecanismos psicológicos subyacentes deberían ser tenidos en consideración para alentar campañas publicitarias preventivas de este tipo de delito, en especial en tiempos post-pandemia, cuando sean abiertas las fronteras y las personas se movilicen para salir de la difícil situación económica en que las consecuencias de la Covid-19 les haya sumido.

\subsection{Elementos psicosociales y criminológicos para la reintegración de los reclusos que retornan a su país de origen}

El contacto con las personas que han pasado por Restauravidas nos permite detectar ciertas cualidades especialmente llamativas derivadas de la experiencia que han vivido; podría ser esperable un mayor nivel de deterioro y afectación, dada tal experiencia vivida y, aunque es cierto que existe un marcado deterioro físico, a nivel general (ostensiblemente visible y narrado por ellos), la afectación emocional permanece relativamente preservada, por lo que merece su análisis, a fin de encontrar las claves de este fenómeno.

El concepto central para el estudio del hecho mencionado es la resiliencia, a través de diferentes cualidades que componen esta capacidad humana. La resiliencia será puesta en relación con el bienestar emocional 
de los individuos que componen la muestra (entendido como un estado de ánimo positivo), según sean categorizados en uno u otro nivel de resiliencia (alta/media/baja) y también se analizará su relación con otro hecho: el relato de una experiencia transformativa fruto de la vivencia traumática.

Además, dado el enfoque restaurativo del presente estudio, serán analizados aspectos relacionados con los procesos de responsabilización y reparación, especialmente a nivel familiar, procesos necesarios para la recuperación de estas relaciones.

A continuación serán presentados todos estos conceptos y puestos en relación entre sí, dado que han sido encontradas interrelaciones significativas.

\subsubsection{Resiliencia}

En general, el ser humano tiene un poder de adaptación ante la adversidad comprendido dentro de un continuo que va de menor a mayor resiliencia. En el tema que nos ocupa sería el proceso de competencia donde el recluso debe adaptarse positivamente a la realidad que conlleva el estar cumpliendo una condena en prisión, caracterizada además por una serie de agravantes en los condicionantes del encierro, que convierten esta experiencia en especialmente traumática. Según Luthar, Cicchetti, y Becker (2000), la resiliencia es una adaptación positiva pese a la adversidad. Estos autores enfatizan los dos elementos que la constituyen, que son la adversidad significativa y la adaptación positiva.

Otros autores ponen el acento en la forma en que esta adaptación se produce, entendiendo la resiliencia como la capacidad de reponerse de las situaciones adversas y estresantes con rapidez y flexibilidad (Tugade y Fredrikson, 2004). Estos autores señalan una serie de características que suelen definir a personas altamente resilientes, y que es posible encontrar en gran parte de los individuos que han formado parte de esta investigación. Algunas de estas características, entre otras, van a operativizar el concepto de resiliencia en este estudio; siguiendo con la propuesta de Tugade y Fredrikson (2004), según su metaanálisis acerca de diferentes estudios que analizan resiliencia, y que resultan de especial aplicación a la muestra seleccionada, estos componentes de resiliencia son: apertura a la experiencia, optimismo, uso del humor para elicitar estados emocionales positivos y actitud energética en el afrontamiento de la vida cotidiana.

\section{a. Apertura a la experiencia}

La apertura a la experiencia, conocido factor de personalidad dentro del Modelo de los Cinco Grandes (Big Five Model atribuido al psicólogo 
estadounidense Louis Leon Thurstone en $1933^{14}$, y que sigue vigente en la actualidad como manera de explicar la personalidad humana), hace referencia, entre otras cualidades, a la disposición del individuo a la búsqueda de nuevas experiencias, incluso asumiendo riesgos; también a la capacidad de adaptarse al medio de una manera flexible, aportando soluciones creativas a las dificultades de la vida cotidiana.

Todos los individuos que han formado parte de esta investigación $(n=21)$ se han encontrado con una situación difícil en sus vidas y han decidido optar por una solución «creativa» para resolver la misma. Podría decirse que han demostrado ser personas abiertas a la experiencia, como revela el hecho de que hayan optado por lanzarse a lo desconocido en la mayoría de los casos ${ }^{15}$, cometiendo un delito con un elevado nivel de riesgo y alta probabilidad de fracaso (detención y condena). Esta cualidad no habla de lo acertado de tales «soluciones creativas», las cuales han supuesto para estas personas el mayor de sus problemas.

\section{b. Optimismo}

Numerosos estudios relacionan el optimismo con la capacidad de ajuste del individuo frente a la adversidad (Diener y Lucas, 1999; Seligman, 2003), entendiendo optimismo como la experimentación de emociones positivas y la capacidad de poner el foco en la propias aptitudes para hacer frente las dificultades, a través del control personal y el afrontamiento racional de los problemas, desde la conciencia de la magnitud de tales retos, y no desde una visión ingenua, de solución mágica de los mismos (Avia y Vázquez, 1998; Seligman, 1998).

No obstante, según señala $\mathrm{M}^{\mathrm{a}}$ Dolores Avia en su reconceptualización del concepto «optimismo inteligente», éste viene caracterizado por la tendencia del individuo a cierto sesgo autoindulgente, por el que anticipa un futuro más prometedor. Parece que esa visión más esperanzadora cumple la función de profecía autocumplida, lo cual conlleva resultados más favorables y escenarios más halagüeños. Los beneficios de este sesgo positivo fueron demostrados en 2002 por Bonanno, Field, Kovacevic y Kaltman en un estudio llevado a cabo con población civil bosnia que sufrió la Guerra de los Balcanes, al encontrar que personas con esta tendencia presentaron un ajuste más positivo que aquellas que no contaban con esta cualidad (Vera, Carbelo y Vecina 2006).

${ }^{14}$ Los vectores de la mente. Discurso del presidente ante la American Psychological Association, reunión de Chicago, septiembre de 1933.

15 Según los datos estadísticos ya presentados, el 71\% de las 21 personas que componen la muestra, son delincuentes primarios. 
Podemos afirmar que este optimismo, presente en un 57\% $(n=12)$ de las 21 personas de la muestra, ha ayudado a estas personas a salir adelante y recuperarse de la situación de trauma que han debido afrontar.

\section{c. Humor}

El sentido del humor es entendido como una fortaleza del ser humano con múltiples funciones personales y sociales, al servir de vehículo de comunicación, así como tratarse de un mecanismo de liberación de ansiedad, tensión e inseguridad (Sanz, 2002). El uso del humor supone una herramienta de amplio valor al permitir la regulación del estado de ánimo, incluso en situaciones de alto nivel de estrés, ya que promueve el bienestar emocional y disminuye las sensaciones desagradables provocadas por las dificultades a las que el individuo debe enfrentarse (Losada y Lacasta, 2019).

En nuestra muestra de 21 sujetos, encontramos un $71 \%$ de individuos $(n=15)$ que manifiestan un amplio sentido del humor, tanto en la dinámica relacional dentro del grupo, como en las interpretaciones realizadas de situaciones de alto nivel de impacto: el relato de experiencias con importante potencial traumatizante desde un prisma cómico, desdramatizador. Posiblemente esta capacidad, junto con el optimismo anteriormente mencionado han resultado potentes herramientas de supervivencia y recuperación.

d. Actitud energética en el afrontamiento de la vida cotidiana

Podría ser entendida como la tendencia a la percepción de control, frente a la indefensión a la hora de afrontar la vida, incluso en sus momentos más difíciles y en las situaciones donde la capacidad objetiva de control sobre la situación es limitada. Desde esta óptica, las personas que se caracterizan por esta actitud energética adoptan una disposición más proactiva, y conectan y confían en sus propias aptitudes para sobrellevar el trance.

Al parecer, no se trata de una capacidad tan común, puesto que únicamente el 24\% ( $n=5)$ de los individuos que componen la muestra de este estudio cuentan con esta cualidad, la cual se convierte en el componente caracterizador de un alto nivel de resiliencia, según los datos analizados.

Puestos todos estos elementos en relación con el concepto central, la resiliencia, es posible asegurar que del total de individuos que componen la muestra, el 24\% de ellos ( $n=5)$ presentan una alta resiliencia, al contar con los cuatro componentes que describen el concepto, el 57\% $(\mathrm{n}=12)$ cuentan con una resiliencia media, siendo conceptualizada como resiliencia medioalta $(n=6)$, al presentar tres de los cuatro componentes, y resiliencia mediabaja, en el caso de que sólo cuenten con dos de los cuatro componentes $(n=6)$. El caso de resiliencia baja se atribuye a aquellos participantes que 
únicamente presentan uno de los componentes, en este caso, la apertura a la experiencia, suponiendo un 19\% de la muestra (n=4) (gráfico 1).

\subsubsection{Experiencia transformativa}

La motivación para el análisis de este fenómeno surge de la detección del mismo a través de la narración de experiencias similares por parte de diferentes integrantes del grupo que compone Restauravidas. Estas personas relatan haber vivido experiencias transformativas como consecuencia del encierro en el extranjero, junto con el afrontamiento de dificultades para las que no estaban preparados. Son descritas tales experiencias como cambios en la forma de ver el mundo, su relación con los demás y de percibirse y reconocerse a sí mismos (self).

\section{Gráfico 1. Nivel de resiliencia}

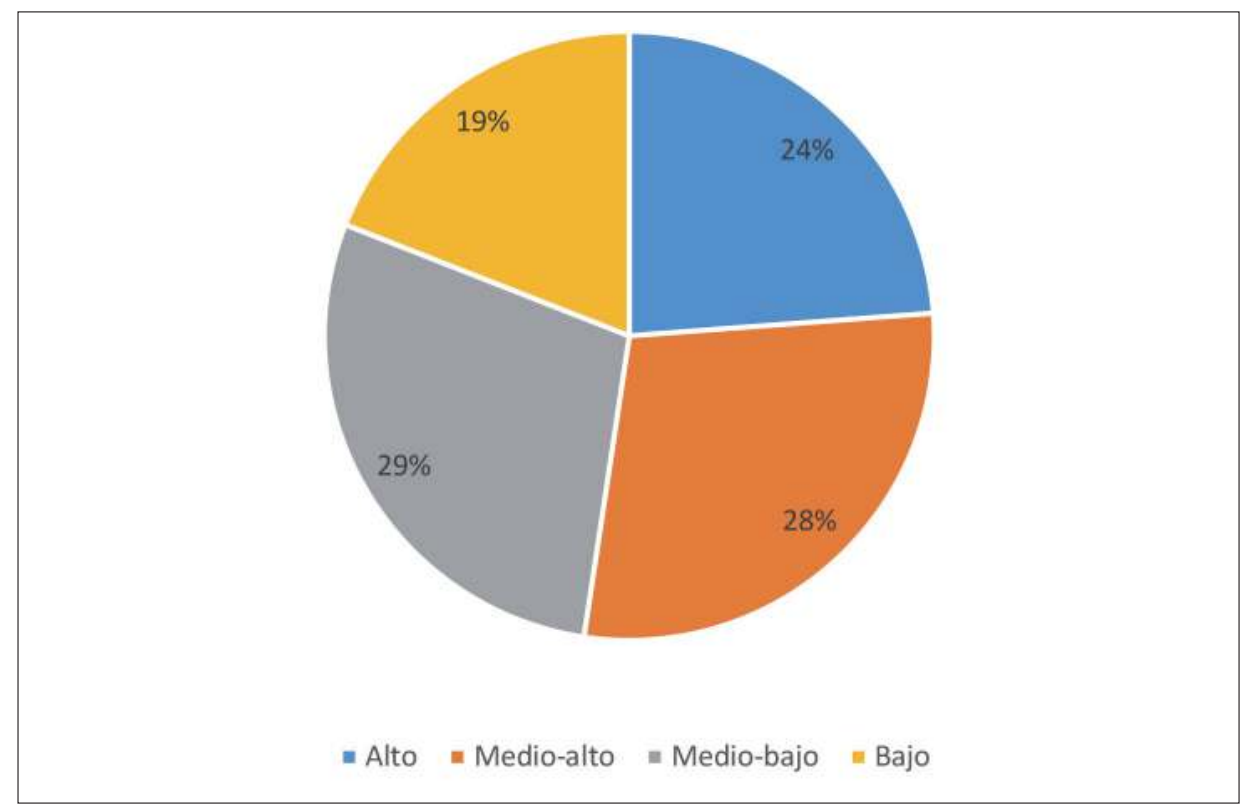

Fuente: elaboración propia a partir de los datos arrojados por el Programa Restauravidas.

En este sentido, se postula la existencia de un conjunto de creencias esenciales que las personas ostentan sobre sí mismas, el mundo y los otros. Estas creencias se enraízan en la experiencia emocional y se sostienen a pesar de evidencias reales que las contradicen. Ejemplo de ello es que pese a que las personas generalmente están de acuerdo, racionalmente, en lo que respecta a la injusticia predominante en el 
mundo, llegando incluso a verbalizarlo, cuando tiene lugar una desgracia que provoca activación emocional, tienden a hacer una atribución de responsabilidad parcial en relación con lo ocurrido (por ej. «algo habrá hecho»), en tanto que constituye una forma de defensa de la creencia básica por la cual uno recibe lo que se merece y no está indefenso ante el azar (Páez, Morales y Fernández, 2007).

Existen determinados autores que hablan de esta experiencia transformativa conceptualizándolo como "crecimiento postraumático», el cual hace referencia al cambio positivo que el ser humano experimenta como resultado de la lucha por la supervivencia a partir de la vivencia de un acontecimiento traumático (Calhoun y Tedeschi, 1999).

Así, la experiencia transformativa en relación al self viene determinada por un cambio actitudinal hacia una mayor serenidad, paciencia, humildad y capacidad reflexiva ante los acontecimientos de la vida; también es mencionada una mayor capacidad de autocontrol («descubrir tu propia fuerza de voluntad»), que les facilita hitos como la renuncia a consumos de diferentes tipos, en algunos casos referidos a alcohol, en otros a cocaína, incluso el consumo combinado, hábitos que presentes en los últimos años de sus vidas y que habían sido detectados como causantes de la situación actual, de alguna manera.

En relación a la transformación referida a las relaciones personales y sociales, es mencionado este cambio como una nueva manera de valorar estas relaciones, dando importancia a cuestiones de relevancia que anteriormente eran despreciadas o bien trivializadas, como los seres queridos. Igualmente es narrado el efecto contrario: la minimización del efecto pernicioso que relaciones sociales potencialmente dañinas puedan ejercer, y que habrían tenido un importante impacto en "su vida anterior» (distanciamientos, rechazo debido al estigma, etc.).

En cuanto a la transformación en la percepción del mundo, las personas que narran este hecho, señalan una mayor capacidad para valorar cosas que anteriormente habían dado por vulgares o carentes de tal valor, cosas pequeñas como la comida, el propio país, o bien de mayor magnitud como los derechos humanos, ampliamente vulnerados durante el encierro en el extranjero, la conciencia de libertad, así como las cosas de la vida que es posible hacer en este estado.

Del total de las 21 personas elegidas para el presente estudio, el 43\% $(n=9)$ de ellas relatan experiencias transformativas, o crecimiento postraumático, en diferentes niveles. El 24\% $(n=5)$ describen esta transformación en los tres ámbitos señalados (el propio self, las relaciones y el mundo), mientras que el 19\% ( $\mathrm{n}=4)$ lo señalan sólo en alguno de ellos, es decir, detectan un cambio significativo en relación a cómo vivían determinados aspectos antes de la condena, más bien relacionado con ese cambio de percepción hacia el exterior (las relaciones y el mundo), siendo que la experiencia de transformación no se vive como un cambio 


\section{Gráfico 2. Experiencia transformativa}

- No experiencia transformativa

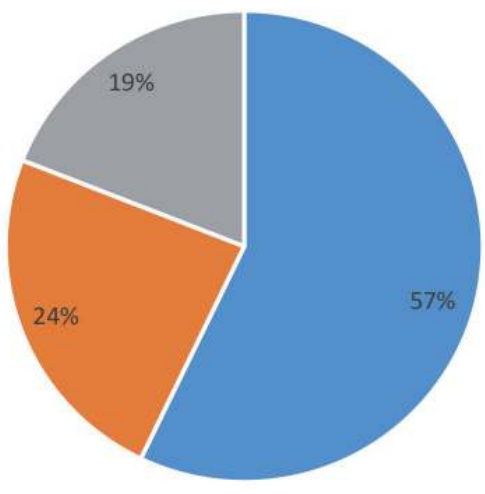

Fuente: elaboración propia a partir de los datos arrojados por el Programa Restauravidas.

global, integral y profundo, que incluya un cambio en el autoconcepto. Por último, tal y como se refleja en el gráfico 2, el 57\% $(\mathrm{n}=12)$-más de la mitad de los participantes- del grupo Restauravidas no han vivido una experiencia transformativa.

Algunos relatos de ejemplos de transformación integral:

"Empecé a sentirme libre, incluso estando encerrado y bajo esas circunstancias; me di cuenta de que todo está en tu cabeza, empecé a leer y a escuchar, a darme cuenta de que estaba rodeado de personas, antes también, pero no me interesaban, no las escuchaba y, aunque necesitaba y deseaba salir de aquella situación terrorífica, me sentía en paz porque sabía que una vida mejor me esperaba. Puedo decir que esa condena me liberó». Preso en Perú $\mathrm{n}^{\circ} 9$.

"Descubri cosas ocultas dentro de mi y mi alrededor. He descubierto mi paciencia, mi fuerza de voluntad... He venido en definitiva con otros valores, soy más humano - incluso hasta mi novia me lo dice. En la calle también hay una gente buenísima. Cuanto tocas fondo consigues valorar muchas de las buenas cosas que tenías antes en tu vida; iqué poco valoramos lo bien que se vive en España!». Preso en Perú no 12.

Algunos relatos de ejemplos de transformación parcial:

"Encontré gente buena, que me ayudó sin pretender nada a cambio, nunca había pensado que la gente pudiese hacer esto». Preso en Perú nº 10. 
"Viví un infierno, pero estoy vivo, y recuperando mis derechos, que no me habia dado cuenta de lo importante que es el respeto a los derechos tuyos $y$ de los demás». Preso en Venezuela ${ }^{\circ} 1$.

"Valoras mucho cualquier comida que no sea arroz, que he estado comiendo durante 6 años y pico y no quiero volver a probar icon la única excepción de la paella de marisco!». Preso en Brasil no 1.

$\mathrm{Al}$ analizar los componentes descritos, que han sido operativizados como definitorios del concepto de resiliencia, es posible detectar una significativa relación positiva entre la presencia de estos componentes y la experiencia de transformación, o crecimiento postraumático: las 5 personas que describen la transformación integral, presentan los cuatro componentes seleccionados que definen la resiliencia, esto es, apertura a la experiencia, optimismo, uso del humor y actitud vital energética.

En cuanto a las 4 personas restantes, todas cuentan con diferentes combinaciones de estos elementos, siendo la cualidad de actitud vital energética la diferenciadora, es decir, se trata de un componente presente en todos los individuos de transformación integral, que permanece ausente en el grupo de transformación parcial y que se convierte por lo tanto, según este análisis, en el componente esencial para la experimentación de la mencionada transformación integral, aplicable a los tres ámbitos descritos.

Tabla 1. Componentes de resiliencia y su relación con la experiencia transformativa

\begin{tabular}{|c|c|c|c|c|c|c|}
\hline Individuos & $\begin{array}{c}\text { Apertura } \\
\text { a la expe- } \\
\text { riencia }\end{array}$ & Optimismo & Humor & $\begin{array}{c}\text { Actitud } \\
\text { energética }\end{array}$ & $\begin{array}{c}\text { Experiencia } \\
\text { transforma- } \\
\text { tiva parcial }\end{array}$ & $\begin{array}{c}\text { Experien- } \\
\text { cia trans- } \\
\text { formativa } \\
\text { integral }\end{array}$ \\
\hline 1. & $\mathrm{X}$ & $\mathrm{X}$ & - & - & - & - \\
\hline 2. & $\mathrm{X}$ & $\mathrm{X}$ & $\mathrm{X}$ & - & - & - \\
\hline 3. & $\mathrm{X}$ & - & - & - & $\mathrm{X}$ & - \\
\hline 4. & $\mathrm{X}$ & - & $\mathrm{X}$ & - & - & - \\
\hline 5. & $\mathrm{X}$ & $\mathrm{X}$ & $\mathrm{X}$ & - & $\mathrm{X}$ & - \\
\hline 6. & $\mathrm{X}$ & $\mathrm{X}$ & $\mathrm{X}$ & $\mathrm{X}$ & - & $\mathrm{X}$ \\
\hline 7. & $\mathrm{X}$ & $\mathrm{X}$ & - & - & $\mathrm{X}$ & - \\
\hline 8. & $\mathrm{X}$ & - & $\mathrm{X}$ & - & - & - \\
\hline
\end{tabular}




\begin{tabular}{|c|c|c|c|c|c|c|}
\hline Individuos & $\begin{array}{l}\text { Apertura } \\
\text { a la expe- } \\
\text { riencia }\end{array}$ & Optimismo & Humor & $\begin{array}{c}\text { Actitud } \\
\text { energética }\end{array}$ & $\begin{array}{l}\text { Experiencia } \\
\text { transforma- } \\
\text { tiva parcial }\end{array}$ & $\begin{array}{c}\text { Experien- } \\
\text { cia trans- } \\
\text { formativa } \\
\text { integral }\end{array}$ \\
\hline 9. & $\mathrm{X}$ & $\mathrm{X}$ & $\mathrm{X}$ & $\mathrm{X}$ & - & $\mathrm{X}$ \\
\hline 10. & $\mathrm{X}$ & - & - & - & - & - \\
\hline 11. & $\mathrm{X}$ & $\mathrm{X}$ & $\mathrm{X}$ & - & - & - \\
\hline 12. & $\mathrm{X}$ & - & $\mathrm{X}$ & $\mathrm{X}$ & - & - \\
\hline 13. & $\mathrm{X}$ & $\mathrm{X}$ & $\mathrm{X}$ & $\mathrm{X}$ & - & $\mathrm{X}$ \\
\hline 14. & $\mathrm{X}$ & - & - & - & - & - \\
\hline 15. & $\mathrm{X}$ & - & $\mathrm{X}$ & - & - & - \\
\hline 16. & $\mathrm{X}$ & - & $\mathrm{X}$ & - & - & - \\
\hline 17. & $\mathrm{X}$ & $\mathrm{X}$ & $\mathrm{X}$ & - & - & - \\
\hline 18. & $\mathrm{X}$ & - & - & - & - & - \\
\hline 19. & $\mathrm{X}$ & $\mathrm{X}$ & $\mathrm{X}$ & $\mathrm{X}$ & - & $\mathrm{X}$ \\
\hline 20. & $\mathrm{X}$ & $\mathrm{X}$ & $\mathrm{X}$ & - & $\mathrm{X}$ & - \\
\hline 21. & $\mathrm{X}$ & $\mathrm{X}$ & $\mathrm{X}$ & $\mathrm{X}$ & - & $\mathrm{X}$ \\
\hline $\mathrm{n}$ & 21 & 12 & 15 & 5 & 4 & 5 \\
\hline
\end{tabular}

Fuente: elaboración propia a partir de los datos arrojados por el Programa Restauravidas.

\subsubsection{Responsabilización}

Se trata de un concepto de extraordinaria centralidad en justicia restaurativa, que apela directamente al rol auto-atribuido por la persona ofensora, victimaria, en relación al delito cometido y el daño causado.

La responsabilización supone la asunción de ese daño, el malestar (pesar, dolor, arrepentimiento) por las consecuencias del mismo, no sólo en el entorno más íntimo, incluidas las consecuencias vividas en las propias carnes; se refiere especialmente a la conciencia de ese impacto sobre la persona o personas directamente dañadas por el delito (víctima/s), y también a ese efecto a un nivel macro, afectando a la comunidad en la que ese daño impacta. 
La conciencia de este daño genera una necesidad de reparación del mismo, no sólo por la posibilidad de obtener beneficios penitenciaros, que pudieran resultar del proceso de reparación, caso de darse esta consecuencia, sino especialmente por la empatía que el dolor de la persona víctima genera sobre la persona ofensora, junto con la motivación por reparar ese daño (Maglione, 2017; Olalde, 2015; Pascual, 2013).

En el análisis de casos que presentamos, ha sido operativizado el grado de responsabilización como alta, media o inexistente según la persona haya sido capaz de expresar estas conclusiones de manera independiente, fruto de la reflexión profunda acaecida en las largas horas de encierro (alta responsabilización, $\mathrm{n}=7$, correspondiente a un 33\% del total de la muestra). Curiosamente las personas que presentan esta cualidad de alta responsabilización relatan todas ellas experiencias transformativas de su self como consecuencia de su estado en prisión: abandono de adicciones, reconciliación consigo mismo y cambio de rumbo de vida.

El grupo perteneciente a lo que se ha venido a denominar como responsabilización media $(n=3$, correspondiente al 14\%), vendría formado por las personas que expresan tales conclusiones gracias a la reflexión guiada por las profesionales de justicia restaurativa que acompañan a lo lardo de todo el proceso. El grupo de responsabilización inexistente está conformado por aquellas personas que únicamente contemplan las consecuencias del delito en el nivel más micro y próximo $(n=11,53 \%)$.

Estos datos nos demuestran que la justicia restaurativa, con todo su potencial, no resulta accesible a todas las personas, por el simple hecho de haber participado en el delito. Este trabajo en responsabilización, como se ha señalado, es escurridizo. No obstante, se trata de una semilla plantada, la cual sigue su propio ritmo; a veces no sufre cambios, a veces ofrece sus frutos de manera espontánea, en un momento posterior e inesperado.

A la vista de los resultados obtenidos, la relación más significativa es hallada entre la mencionada experiencia de transformación y el proceso de responsabilización. Estos resultados guardan coherencia con la experiencia vivida por la persona: de las 9 personas que experimentan transformación en su percepción y vivencia de alguno de los tres ámbitos señalados (self, relaciones y visión del mundo), todas ellas (43\%) son capaces de verbalizar aspectos relativos a su responsabilidad en el delito como hecho trascendente más allá del propio impacto y el impacto en el entorno más próximo, que suele incluir a familiares más cercanos, tal que padres, hijos y/o pareja; así, se muestran capaces de mirarse a sí mismos como agentes necesarios para que el delito contra la salud pública se ejecute y se mantenga, asumiendo la parte de responsabilidad que este rol les asigna. Es posible detectar este fenómeno a través de manifestaciones como las que siguen: 


\section{Gráfico 3. Grado de responsabilización}

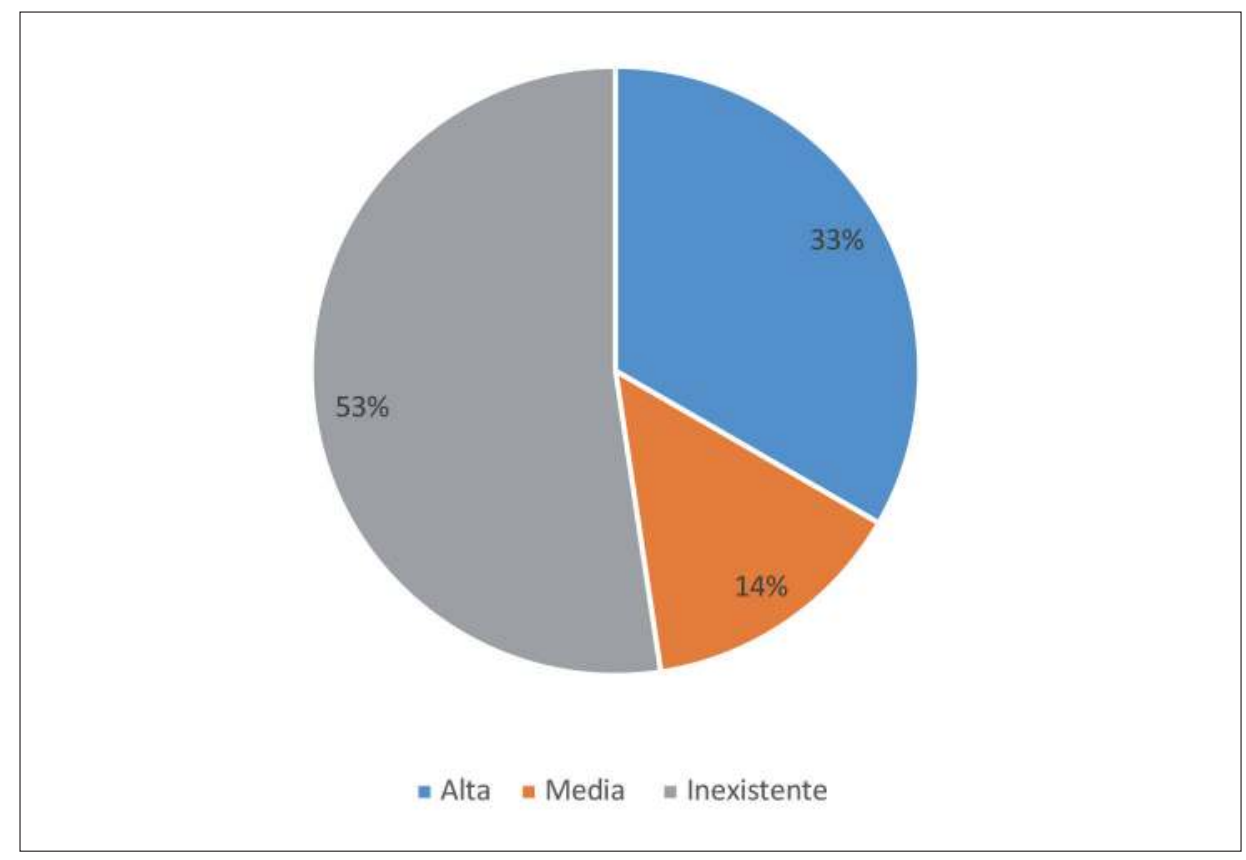

Fuente: elaboración propia a partir de los datos arrojados por el Programa Restauravidas.

"Estando encerrado pensaba mucho en las madres de las personas que consumen y que pierden su alma». Preso en Perú $\mathrm{n}^{\circ} 5$.

"Lo he pasado fatal estando alli, en la miseria e infierno en el que me he visto, y también pensando en mi familia, que no se merece que les haya hecho esto, pero también he sufrido muchísimo pensando que había formado parte de ese engranaje del tráfico de drogas». Preso en República Dominicana $\mathrm{n}^{\mathrm{o}} 1$.

"Siento dolor y enfado conmigo mismo por haber "caído en las redes» de mafiosos que se aprovechan de nosotros, personas necesitadas y desesperadas; nosotros mantenemos esa mafia que tanto daño hace». Preso en Venezuela $\mathrm{n}^{\circ} 1$.

\subsubsection{Bienestar emocional}

El bienestar emocional, es definido según la Organización Mundial de la Salud (OMS) como un «estado de completo bienestar físico, mental y social, y no solamente la ausencia de afecciones o enfermedades» pudiendo ser entendido como un estado de ánimo positivo a la hora de relacionarse y de estar consigo mismo, que permite «que el individuo realiza sus capacidades, supera el estrés normal de la vida, trabaja de 
forma productiva y fructífera, y aporta algo a su comunidad» ${ }^{16}$ (OMS, 2013, pág. 5).

En el presente estudio, ha sido considerado el grado de bienestar emocional a partir de verbalizaciones de los participantes, así como a través de la observación y registro de conductas y actitudes de emocionalidad positiva. Tales indicadores han sido detectados en relación a diferentes elementos especialmente significativos, dadas las circunstancias de estas personas. Por un lado, en cuanto al estado físico y mental (incluso con la existencia de problemas de salud, por los que reciben el correspondiente tratamiento, y que han sido desatendidos en la mayor parte de los casos durante la estancia en el extranjero), en relación a la situación actual (satisfacción por el regreso a España, a pesar de que sea en condiciones de encarcelamiento, junto con las acciones encaminadas a recuperar los vínculos familiares), y también respecto al futuro (perspectivas de retorno a centros de cumplimiento más próximos a los seres queridos, la eventual excarcelación y las posibilidades de readaptación a la vida en libertad).

De las 21 personas que constituyen la muestra, el 48\% ( $\mathrm{n}=10)$ dice encontrarse en buen estado anímico, sentirse contentos y agradecidos por el regreso a su país, aunque sea para seguir adelante con su condena, y presentar buenas perspectivas de futuro. Además, estas verbalizaciones coinciden con el criterio de las profesionales responsables del proyecto. Dada la presencia de ambos hechos, podría decirse que estas 10 personas presentan un alto grado de bienestar emocional.

Existe un 33\% ( $n=7)$ que han sido clasificadas dentro de un estado de bienestar emocional medio, caracterizado por verbalizaciones y actitudes observadas de preocupación y de cierto malestar en relación a alguno de los elementos anteriormente citados (estado físico y mental, situación actual y perspectivas de futuro).

A la vez, el 19\% restante $(n=4)$ presentan un estado de ánimo bajo acerca de los tres elementos en cuestión, detectado tanto en sus propias verbalizaciones como en la observación directa.

Hemos partido de la suposición de que las personas con un alto nivel de resiliencia para hacer frente a la vida en prisión, presentarán un mayor bienestar emocional a su regreso a España, incluso con la circunstancia de mantenimiento de la condición de encarcelamiento. Poniendo por lo tanto en relación ambos conceptos, se encuentra que el total de personas que han puntuado alto en resiliencia $(n=5)$, se hallan en el rango de alto bienestar emocional, las 4 restantes que también han sido incluidas en este rango de bienestar emocional han sido consi-

16 Organización Mundial de la Salud, Plan de acción sobre salud mental 2013-2020, Ginebra, 2013, disponible en https://www.who.int/topics/mental_health/es/ 
deradas personas con una resiliencia media-alta. Este dato nos podría llevar a pensar acerca de la existencia de una relación positiva significativa entre ambos conceptos, y confirmar por tanto esta asociación (gráfico 4).

\subsubsection{Revinculación familiar y reparación}

Como se ha apuntado anteriormente, uno de los objetivos de Restauravidas es detectar aquellas relaciones significativas sobre las que las personas necesitan trabajar para reparar el daño generado como consecuencia del delito y la condena, y lograr la reconciliación con los seres queridos.

\section{Gráfico 4. Bienestar emocional}

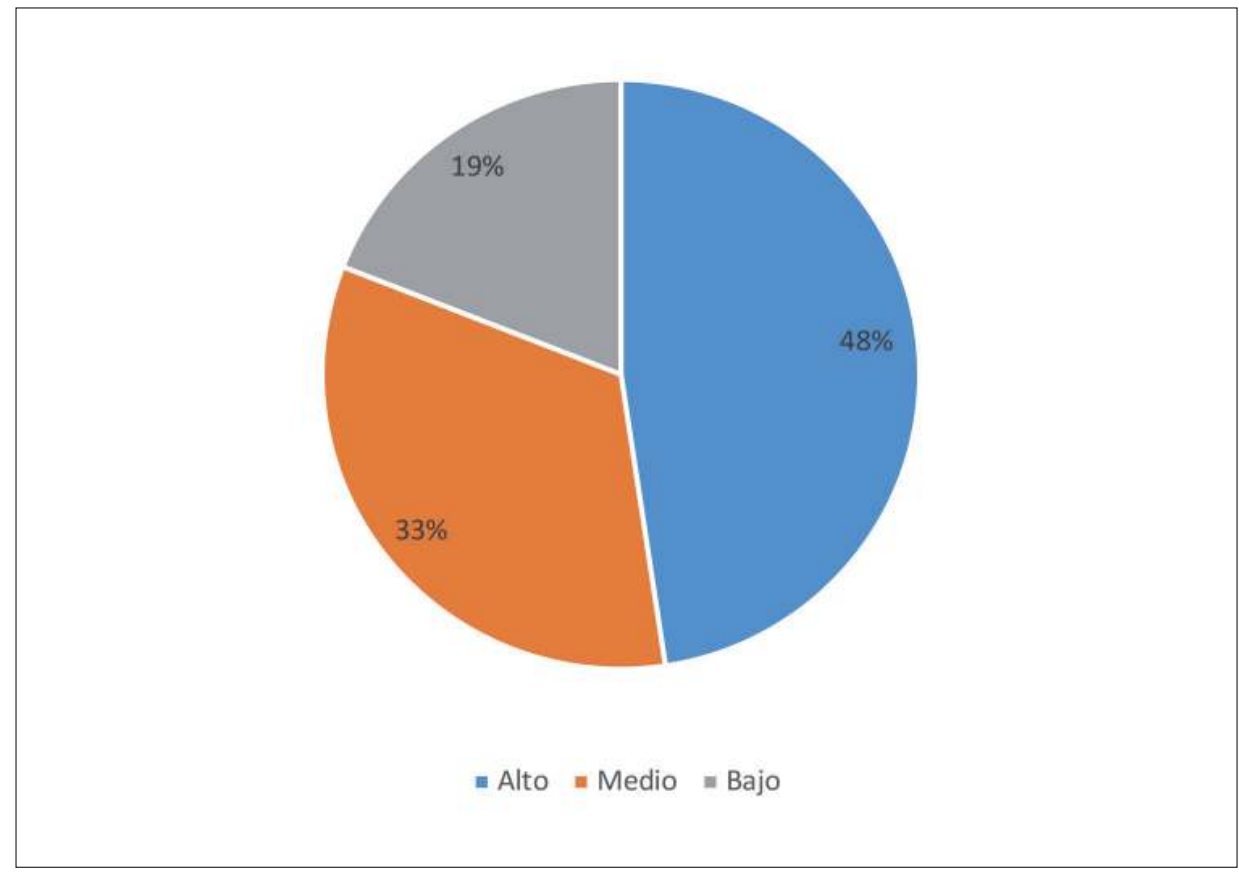

Fuente: elaboración propia a partir de los datos arrojados por el Programa Restauravidas.

Existe amplia documentación (Codd, 2006; García-Borés, Font, Fernández, Escurriol, Roig, Leyton y Moreno, 2006; Ibáñez I Roig y Pedrosa, 2018; Martí y Cid, 2015; Maruna, 2001) acerca de la importancia del soporte familiar de cara a la reinserción de las personas privadas de libertad. Los lazos familiares suponen un sustento imprescindible para una reincorporación exitosa; no existe duda acerca de este hecho, a pesar 
de que puedan existir diferentes explicaciones para el mismo ${ }^{17}$. Y lo que es más, el estado de estas relaciones familiares, la recuperación de los lazos emocionales, resulta fundamental para el bienestar emocional de los individuos en prisión.

Ya hemos mencionado anteriormente que estas personas han tomado una decisión errónea, considerando que el tráfico de droga, delito «bien pagado», podía ser la solución a una situación de desesperación y desesperanza, y pasa a convertirse sin embargo en el inicio de lo que han venido a llamar «un infierno en la tierra». El sufrimiento de esta nueva situación no se queda en ellos. Pilla por sorpresa a familiares y amigos, los cuales deben afrontar la pérdida del ser querido, la readaptación familiar, y las emociones negativas derivadas de este hecho, en mayor o menor medida, según el grado de proximidad y vinculación. Deben lidiar con el miedo, la soledad, el enfado y en ocasiones la culpa y la falsa responsabilidad ${ }^{18}$ por no haber sido capaces de percatarse de lo inminente, incluso de evitarlo. La persona condenada debe afrontar también esta emocionalidad ajena, sumada a la propia. Al volver a España se ve obligado a enfrentarse a todo ello, no sólo «aguantando el chaparrón», sino también entendiendo que debe reparar ese daño, si es que esas relaciones son significativas y pretende cuidarlas y recuperarlas.

Desde un prisma restaurativo, es poco común que los familiares de la persona victimaria sean entendidos como víctimas del delito. Contemplando un delito como el tráfico de drogas, más bien es considerada la sociedad como víctima del mismo, personificada quizá en casos concretos de personas del entorno que hayan sufrido especialmente como consecuencia del consumo de sustancias. Es posiblemente uno de los delitos en los que los y las profesionales de la justicia restaurativa se encuentran con mayores dificultades para acompañar en los procesos de responsabilización y reparación.

Ni el Estatuto de la Víctima ni la Directiva Europea reconocen a la familia de la persona condenada como víctima; no obstante, podemos asegurar que resulta directamente agraviada por las consecuencias de esta condena, en forma de sufrimiento, carencias, incluso estigma (Cabrera y Ríos, 1998). Como se ha apuntado, estas personas victimarias tienen ese

17 Joel Martí y José Cid (2015) realizan una clara exposición en su artículo «Encarcelamiento, lazos familiares y reincidencia. Explorando los límites del familismo» de las tres teorías principales que apoyan esta premisa a saber: apoyo social, control social informal en el curso de la vida y transformación cognitiva. Cada una de ellas, aporta una explicación acerca de los mecanismos subyacentes al rol reinsertador de la familia en personas privadas de libertad.

18 Concepto introducido por Daniel Van Ness en 2005 en el $11^{\circ}$ Congreso para la Prevención del Crimen y la Justicia Criminal en Bangkok, Tailandia para nombrar el fenómeno por el que víctimas y personas que viven las consecuencias del delito de otros, consideran falazmente que han tenido responsabilidad en la comisión del mismo. 
concepto muy claro, ya que han sido testigos de ese sufrimiento familiar y objeto de toda esa emocionalidad negativa, de alta intensidad, que se remueve con el acercamiento a su país, y la recuperación del contacto con los seres queridos.

Restauravidas acompaña en ese proceso de aproximación y revinculación, y dentro de este desarrollo debe trabajarse la reparación por el daño ocasionado. A veces no es detectada esta necesidad, sino que surge más bien como consecuencia de la reflexión guiada.

De las 21 personas participantes en este estudio, únicamente 2 de ellas $(10 \%)$ han desestimado la necesidad de reparación de las relaciones familiares, bien por encontrarse en un estado emocional incapacitante para ahondar en estos aspectos, bien por tratarse de relaciones familiares rotas que la persona no ha deseado recuperar. En el resto de casos, los miembros señalados han sido los progenitores (especialmente la madre), la pareja, los hijos y los hermanos. A pesar de que parte de la metodología de trabajo utilizada para profundizar en este aspecto ha sido la expresión escrita (carta), sólo en 5 ocasiones las personas han utilizado este medio como vehículo de expresión único de ideas, pensamientos y sentimientos; en el resto de casos ha servido más bien como fórmula de organización de ideas para afrontar el diálogo directo, cara a cara, con el propósito de mostrar el arrepentimiento, pedir perdón y por supuesto, expresar el compromiso de no repetir la acción, incluso en caso de extrema necesidad.

En los casos en los que debían ser reparados los hijos e hijas, especialmente cuando son menores, existe un agravante que tiene que ver con una de las funciones de la paternidad y la maternidad, relacionado con lo normativo, la transmisión de valores y la protección. Los padres y madres que se han visto en esta tesitura, han reflexionado de manera profunda acerca de lo que han entendido como una pérdida de legitimidad moral, sintiéndose obligados a decidir entre contarles a sus descendientes dónde han estado y el motivo real de la ausencia, o bien mantenerles en la ignorancia para evitarles ese sufrimiento, ese estigma, y no sentir que deben renunciar a la legitimidad de poner ciertos límites, cuando fuese necesario, los cuales ellos mismos han trasgredido. Pero ¿se puede reparar realmente sin afrontar la verdad? ¿Se puede utilizar la propia experiencia para enseñar y ayudar a entender las consecuencias de determinadas decisiones con un propósito preventivo? Todas estas preguntas, junto con otras, han formado parte del trabajo reflexivo; las respuestas a las mismas han servido de ayuda para crear el contenido de lo que cada uno ha necesitado expresar a los seres queridos, para repararles, revincularse, y aproximarse a cierta paz interior, necesaria para su adaptación tras el retorno, reajustando identidad e integrando lo acontecido como parte de la historia de vida.

La forma en que esta reparación simbólica se ha realizado (19 casos, correspondiente a un $90 \%$ del total de los casos), ha venido en la forma 
de disculpas directas, cara a cara, en 14 de los casos (67\%), en 3 de ellos a través de carta escrita (14\%), y en 2 de estos casos de manera mixta $(9 \%)$, de forma que la carta ha servido a modo de ejercicio reflexivo, a la vez que ensayo encubierto de las disculpas directas, tan necesarias para la reparación y la revinculación.

\section{Gráfico 5. Reparación familiar}

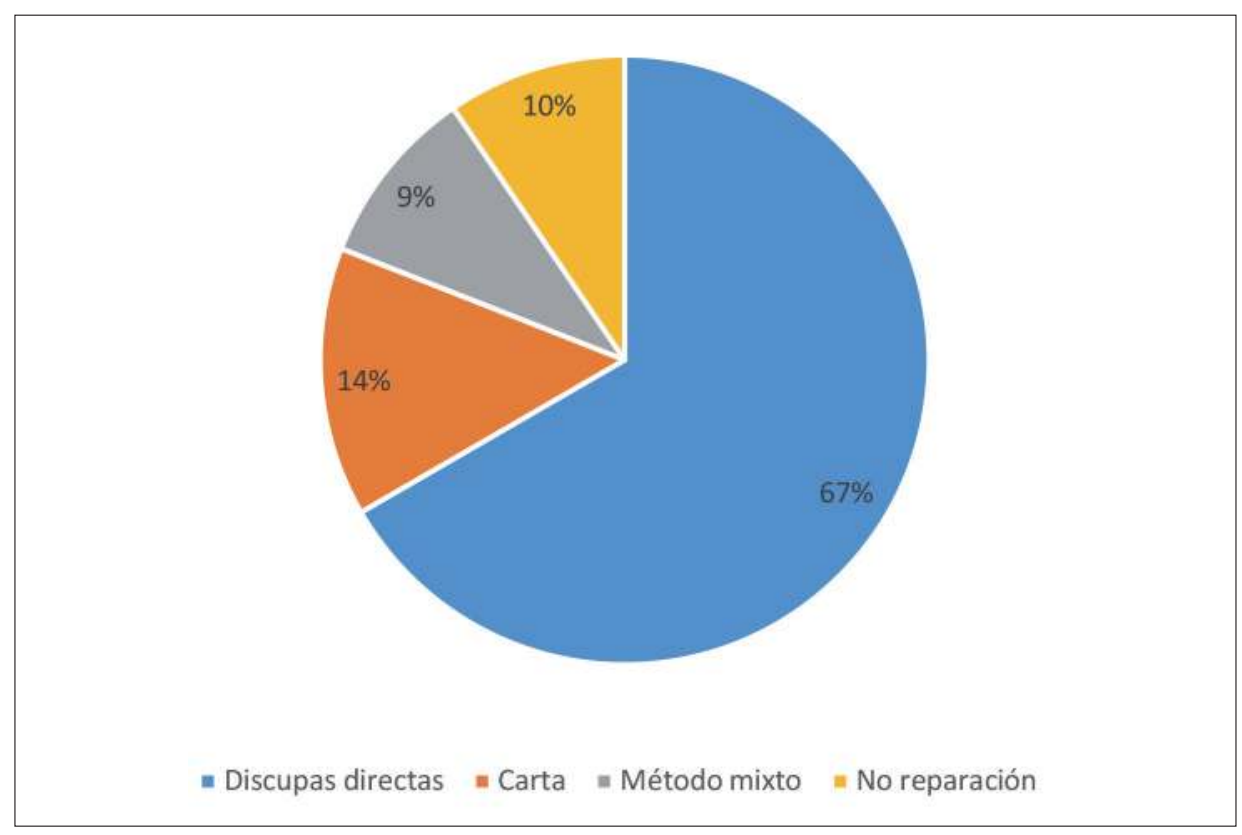

Fuente: elaboración propia a partir de los datos arrojados por el Programa Restauravidas.

\section{Conclusiones}

Tras la realización del análisis de los datos descriptivos provenientes del Programa Restauravidas desde una perspectiva criminológica, psicológica y restaurativa, cabe destacar que los resultados arrojan una serie de conclusiones en relación a las características de las personas españolas que han vivido la experiencia de encierro en el extranjero, como consecuencia de su actividad delictiva debida al tráfico de drogas. Estas conclusiones pueden resumirse de la siguiente manera:

Desde una perspectiva criminológica resulta interesante detenerse en el perfil delictivo tras los datos analizados. Tomando como referencia las personas que han formado parte de este proyecto de investigación $(n=21)$ es posible establecer un perfil delictivo prevalente, representado 
por un varón, entre 46 y 55 años, que se aproxima al delito por primera vez, motivado por la necesidad económica y que no contempla las posibles consecuencias de este delito. En un porcentaje de casos nada despreciable (52\%) estas personas han añadido sufrimiento a la experiencia de su detención al detectar que no sólo habían sido empleados como transporte de droga, hecho que habían aceptado y convenido lucrativamente, sino que además, habían sido utilizados como señuelo para las fuerzas de seguridad, mientras que otra carga de droga de mayor envergadura pasaba los controles mientras ellos eran detenidos.

El dato relativo a la contemplación de las consecuencias que finalmente acaecieron resulta de suma importancia, dado que nos habla de un mecanismo de evitación cognitiva acerca de las graves consecuencias que pueden sobrevenir con una alta probabilidad, una vez es tomada la decisión de participar como «mula» en el delito de tráfico de drogas, especialmente en el caso de delincuentes primarios. Además, se complementa con un mecanismo de minimización de los riesgos de ser detenido, así como de las consecuencias de este hecho (las dramáticas circunstancias del encierro), para delincuentes reincidentes, que permiten que la persona pueda seguir adelante con un plan altamente imprudente con consecuencias negativas, de mayor probabilidad de lo previsible.

Los resultados anteriores deberían ser tenidos en consideración de cara a políticas de sensibilización y prevención, llevadas a cabo por la Administración Central, o bien por otras instituciones, teniendo en cuenta la crisis sanitiria y económica que estamos viviendo tras la Covid-19 y que está aumentando las desigualdades sociales, dado que, a todas luces, se trata de mecanismos psicológicos que están facilitando que personas en situación de desesperanza y desesperación económica tomen este supuesto «camino fácil» como salida de dicha situación, sin considerar las graves y posibles consecuencias para sí mismos y para los suyos.

Desde un punto de vista psicológico, son obtenidos ciertos resultados que se deducen significativos en cuanto a las consecuencias internas que la experiencia de encierro en el extranjero y su retorno a España suponen. Cabe destacar los siguientes:

Analizados ciertos componentes psicológicos de relevancia en esta experiencia, es destacado el papel que la resiliencia tiene en el proceso de reintegración de estas personas en el retorno a su país. En particular, es el factor de resiliencia conocido como actitud energética ante la vida el que parece resultar el determinante de la alta resiliencia, frente a los otros tres factores que componen este constructo.

Además, todas las personas que presentan el componente de actitud energética relatan la vivencia de experiencias transformativas integrales, que afectan a todos los ámbitos centrales de su existencia (visión del mundo, las relaciones personales y cambio en la autopercepción y 
autoconcepto — self-), por lo que se confirma la asociación positiva entre estos dos elementos.

Desde un enfoque restaurativo, otro de los grandes ejes del Programa Restauravidas, ha sido analizado el concepto de responsabilización. En este sentido, el 47\% de los participantes en el estudio asumen algún grado de responsabilización, bien como consecuencia de las largas horas de encierro, soledad, introspección y arrepentimiento (7 personas), bien fruto de su participación en Restauravidas (3 personas) a través de la reflexión guiada. Ambos datos resultan de especial interés: por un lado, las personas que llegan con la conciencia profunda del daño causado en un nivel superior al próximo, como agente de un delito con afectación a gran escala, son personas que han vivido una transformación en su autoconcepto, y reconocen haber vivido una experiencia transformativa, o crecimiento postraumático, que les ha llevado a la decisión de cambio radical en sus vidas, optando por la recuperación de las riendas de su vida y de sus relaciones más significativas. Por otro lado, las otras 3 personas que han contemplado algún grado de responsabilización $(n=3)$ gracias al trabajo reflexivo realizado desde una perspectiva restaurativa confirman el potencial reinsertador y preventivo de la justicia restaurativa, aun a sabiendas que pueda ser rechazada la reinserción por algunos autores como objetivo restaurativo, sino más bien como un «subproducto» por estos procesos, siguiendo las palabras de Howard Zehr (2007) en su Pequeño libro de la justicia restaurativa (p. 14).

Otro de los hallazgos encontrados en este estudio tiene que ver con el papel de la resiliencia en relación al bienestar emocional de las personas, dado que se ha encontrado que, todas las personas que han sido calificadas dentro del rango de resiliencia alta y medio-alta $(n=11)$, admiten encontrarse en un estado óptimo de bienestar, en mayor o menor grado, por lo que queda confirmada la suposición de partida, al hipotetizar que un alto nivel de resiliencia contribuye al bienestar emocional de las personas.

Siguiendo con la perspectiva restaurativa y reinsertadora, el 90\% de las personas participantes en el presente proyecto han realizado acciones de reparación a familiares y relaciones significativas, lo cual ha permitido recuperar lazos, quizá rotos o maltrechos como consecuencia de la detención y la condena, debido a la emocionalidad negativa provocada en la familia. Este hecho, que permite la recuperación de la familia como red de apoyo y sostén, ha contribuido en buena medida al proceso de reinserción de estas personas y su reincorporación a la sociedad de la que una vez salieron.

Todos estos resultados aportados por el proyecto de investigación basado en el Programa Restauravidas. Reintegración en el País de Origen, ponen el foco en una realidad social, acerca de la que existe escasa investigación. A pesar de las limitaciones provenientes del tamaño de la 
muestra y de la metodología basada en el modelo de investigación-acción, es posible considerar tales resultados como una radiografía de la realidad social, y alentar futuros estudios que continúen profundizando en factores de mayor relevancia y servir de apoyo a nuevas medidas preventivas de este tipo de delito, el cual genera un gran daño social y personal.

\section{Bibliografía}

Asnaani, A., Mclean, C. P. y Foa, E. B. (2016). Updating Watson \& Marks (1971): How Has Our Understanding of the Mechanisms of Extinction Learning Evolved and Where Is Our Field Going Next?. Behavior Therapy, 47 (5), 654-668. Recuperado de https://www.sciencedirect. com/science/article/abs/pii/S0005789416000198.

Avia, M. D. y VÁzouez, C. (1998). Optimismo inteligente. Madrid: Editorial Alianza.

BRAVo, O. A. (2011). Las prisiones de la locura. La construcción institucional del preso psiquiátrico. Cali: Editorial Universidad Icesi.

CABrera, P. J. y Ríos, J. C., (1998). Mil voces presas. Madrid: Universidad Pontificia de Comillas.

Chapman, T., Van Hoek, A., Y Wolthuis, A. (2018). The road less travelled. More human approaches to addressing the harm of criminal behavior. Amsterdam: Restorative Justice Nederland.https://www.euforumrj. $\mathrm{org} / \mathrm{sites} /$ default/files/2020-01/the-road-less-travelled-2018.pdf.

CID, J. (2005). The penitentiary system in Spain: The use of imprisonment, living conditions and rehabilitation. Punishment \& Society. 7. 147-166. http://dx.doi.org/10.1177/1462474505050439.

Codd, H. (2007). Prisoners' Families and Resettlement: A Critical Analysis. The Howard Journal, 46(3), págs. 255-263.

Concha, I. (2007). Propuesta de evaluación cualitativa desde la población penal al Tratamiento Psicosocial intramuros. El caso del complejo penitenciario de Valparaíso. Tesis para optar al título de Magíster en Antropología y Desarrollo. Facultad de Ciencias Sociales. Universidad de Chile.

DAVIDSON J.R.T. y FOA, E.B. (1991). Diagnostic issues in posttraumatic stress disorder: considerations for the DSM IV. Journal of Abnormal Psychology. 100(3). 346-355.

De Mesmaecker, V. (2011). Perceptions of justice and fairness in criminal proceedings and restorative encounters: extending theories of procedural justice. Doctoral dissertation. Belgium: KU Leuven Faculty of Law. Recuperado de https://core.ac.uk/download/pdf/34510494.pdf.

Diener, E. y Lucas, R. (1999). Personality and subjective well-being. En D. Kahneman, E. Diener y N. Schwartz (Eds.). Well-being: The 
foundations of Hedonic Psychology. 213- 229. New York: Russell Sage Foundation.

Echeburúa, E., Amor, P. J. y CoRRal, P. (2005). Evaluación del trastorno de estrés postraumático. En V. E. CABALlo (dir.), Manual para la evaluación clínica de los trastornos psicológicos: estrategias de evaluación, problemas infantiles y trastornos de ansiedad (pp. 489-505). Madrid: Pirámide.

García-Borés, P., N., Font, C., Fernández, R., Escurriol, A. Roig, H. LEYTON y MoReno, M. (2006). La cárcel en el entorno familiar. Estudio de las repercusiones del encarcelamiento sobre las familias: problemáticas y necesidades. Observatori del Sistema Penal i els Drets Humans, Barcelona.

Garrido, V. (1982). Psicología y Tratamiento Penitenciario: Una Aproximación. Madrid: Edersa.

Gustafson, D. L. (2018). Encountering «the Other»: Victim Offender Dialogue in Serious Crime. Doctoral dissertation. Belgium. Recuperado de https://lirias.kuleuven.be/1996032?limo=0.

IBÁÑEz I Roig, A. y Pedrosa, A. (2018). Cárcel y familiarismo: ¿Usamos a las familias como agencias de reinserción?. Encrucijadas: Revista Crítica de Ciencias Sociales. 16(9). Recuperado de https://dialnet.unirioja. es/servlet/revista?codigo $=16166$.

LARSON, J. y ZeHR, H. (2007).The ideas of engagement and empowerment. En G. Johnstone, y D. W. Van Ness, (Eds.). Handbook of restorative justice (pp. 41-55). Cullompton: Willan Publishing. https://doi. org/10.1111/j.1468-2311.2009.00562_3.x.

Leal, L., y García, A. (2008). Condiciones objetivas y subjetivas del funcionamiento de la medida destacamento de trabajo desde la perspectiva de los destacamentarios. Capitulo Criminológico. 36(1), 11-37. Recuperado de https://scielo.conicyt.cl/scielo.php?script=sci_ nlinks\&ref $=8374965 \& \mathrm{pid}=$ S0718-0950201200020000200016\&lng=e.

LEWIN, K. (1988). Acción-investigación y problemas de las minorías. Revista de Psicología Social, 3, 229-240.

LuthaR, S., Cicchetti, D. y Becker, B. (2000). The construct of resilience: A critical evaluation and guidelines for future work. Child development. 71, 543-62. https://doi.org/10.1111/1467-8624.00164.

Losada, A. V. y LacASTA, M. (2019). "Sentido del humor y sus beneficios en salud». Calidad de Vida y Salud. 12 (1), 2-22.

Maglione, G. (2017). Embodied victims: An archaeology of the «ideal victim» of restorative justice. Criminology and Criminal Justice. 17 (4), 401-417. 
MARTí, J. y CID, J. (2015). Encarcelamiento, lazos familiares y reincidencia. Explorando los límites del familismo. Revista Internacional de Sociologia, 73(1). http://dx.doi.org/10.3989/ris.2013.02.04.

Maruna, S. (2001). Making Good. How Ex-Convicts Reform and Rebuild their Lives. Washington: American Psychological Association.

Minuchin, S. y Fishman, H. C. (1984). Técnicas de terapia familiar, Barcelona, 1984.

Oкimoto, T. G., y Wenzel, M. (2009). Punishment as restoration of group and offender values following a transgression: Value consensus through symbolic labelling and offender reform. European Journal of Social Psychology. 39 (3), 346-367.

Olalde, A. J. (2015). Estudio multidimensional de algunas prácticas de Justicia Restaurativa en el País Vasco con Lentes de Trabajo Social. Tesis doctoral. Murcia: Universidad de Murcia.

Páez, D., Morales, J. F. y Fernández, I. (2007). Las creencias básicas sobre el mundo social y el yo. En J. F. Morales, M. Moya, E. Gaviria E I. CuADRADO (Coords.). Psicología Social (pp. 195-211). Madrid: Mc-Graw-Hill.

Páez, D., VÁzouez, C. y Echeburúa, E. (2013). Trauma social, afrontamiento comunitario y crecimiento postraumático colectivo. En M. J. Carrasco y B. Charro (Eds.). Crisis, vulnerabilidad y superación. Madrid: Universidad Pontificia de Comillas.

Pascual, E. (coord.). (2013). Los ojos del otro. Encuentros restaurativos entre víctimas y ex miembros de ETA. Madrid: Sal Terrae.

Pranis, K. (2010). Processos Circulares. Teoria e Prática. São Paulo: Palas Athena.

RANGEL, H. (Coord.). (2009). Mapa regional latinoamericano sobre educación en prisiones. Notas para el análisis de la situación y la problemática regional. Francia: Centre international d'études pédagogiques.

Ríos, J. C., Pascual, E. Segovia, J. L., Etxebarria, X., y Lozano, F. (2016). Mediación penal, penitenciaria y encuentros restaurativos. Experiencias para reducir el sufrimiento en el sistema penal. Madrid: Universidad Pontificia de Comillas.

Rodríguez, F. J., García, F., Longoria, B., y Noriega, M. (2014). El Sistema Penitenciario: Un análisis desde el ayer para el mañana. En E. García (Ed.) Manual de Psicopatología Legal y Forense (733-760). México: Manual Moderno.

Ruiz, J. I. (2014). Psicología Social y Justicia. Bogotá: Universidad Nacional de Colombia.

SANZ, J. (2002). El humor como valor terapéutico. Medicina Clínica. 119(19), 734-737. Recuperado de https://www.sciencedirect.com/ science/article/abs/pii/S0025775302735616. 
Seligman M.E.P. (1998). Learned optimism: How to change your mind and your life. (2a. ed.). New York: Pocket Books.

SEligman, M.E.P. (2003). La auténtica felicidad. Barcelona: Vergara.

Sherman, L.W., Strang, H., Mayo-Wilson, E. y BaraK, A. (2015). Are restorative justice conferences effective in reducing repeat offending? Findings from a Campbell systematic review. Journal of quantitative criminology. 31(1), 1-24. https://doi.org/10.1007/s10940-014-9222-9.

Tennant, C. (2006). Life events, stress and depression. En Australian and New Zealand Journal of Psychiatry. 36 (2), 173-182. Recuperado de https://journals.sagepub.com/doi/10.1046/j.1440-1614.2002.01007.x.

Thurstone, L. L. (2003). Los vectores de la mente. En J. M. Gondra RezOLA (Coord.). La psicología moderna: textos básicos para su génesis y desarrollo histórico (pp. 577-598). Bilbao: Desclée de Brouwer.

Tugade, M. M., Y FREDRICKsON, B. L. (2004). Resilient individuals use positive emotions to bounce back from negative emotional experiences. Journal of personality and social psychology. 86(2), 320-333. Recuperado de https://www.ncbi.nlm.nih.gov/pmc/articles/PMC3132556/.

Umbreit, M. S., Vos, B., Coates, R. B., y Lightfoot, E. (2005). Restorative justice in the twenty-first century: A social movement full of opportunities and pitfalls. Marquette Law Review, 89, 251-304.

VAN Ness, D. (2005). An overview of restorative justice around the world. Centre for Justice and Reconciliation at Prison Fellowship International Washington, DC. Workshop 2: Enhancing Criminal Justice Reform, Including Restorative Justice. United Nations 11th Congress on Crime Prevention and Criminal Justice Bangkok, Thailand. https://nacrj.org/index.php?option=com_easyfolderlistingpro\&view=download\&format=raw\&data =eNptkE1rwzAMhv-K0W mDQZ2uXVf1VNhphw122bG4iZIYkjhITtox9t9cJ1wnKbvsYNCH3 0ev5DDL8FvwCaEMTUEMB8HNBsG3rlwiWTFJGDjXqKX2TCyrD5IY2EU_knkdJPqckkYxMAjxTJGphGBvrWpQ2d-EHcLpNNVS9jxLO9dOKPXCF9_Q15Kkni8mYwhZtrULganpXaxTZhEWUKnCG2. i3Rjh25n0kHj1dTCjNP-7NkcPQFSbWZD4DN4W5e3GdGfW9kciDWVu7vU-8RwS6xiXqi3 LxQdfe653g4NGmddWMi9HldUud_ j5P1b0qmJKN-QK6VxVC1ajRn1_7GX2r.

Vera, B., Carbelo, B., Vecina, M. L. (2006). La experiencia traumática desde la psicología positiva: resiliencia y crecimiento postraumático. Papeles del Psicólogo, 27(1), 40-49. Recuperado de http://www.redalyc. org/articulo.oa?id=77827106.

Visher, C. A. y O'CONNELl, D. J. (2012). Incarceration and inmates' selfperceptions about returning home. Journal of Criminal Justice. 40(5), 386-393. Recuperado de https://psycnet.apa.org/doi/10.1016/j.jcrimjus.2012.06.007. 
Wemmers, J.A. (2019). From restorative to transformative justice: The relevance of therapeutical jurisprudence for restorative justice. The International Journal of Restorative Justice, 2(3), 470-477.

ZeHr, H. (1990). Changing lenses: A new focus for crime and justice. Scottdale: Herald Press.

ZeHR, H. (2007). El pequeño libro de la justicia restaurativa, Intercourse Good Books.

\section{Normativa y documentos oficiales}

Comité de Ministros del Consejo de Europa Referente a La Justicia Restaurativa en Asuntos Penales (2018). Recomendación No. R (99) 19. Recuperado de https: //www.euromed-justice.eu/en/system/ files/20100715121918_RecommendationNo.R\%2899\%2919_EN.pdf.

INFORME DEL MiNISTERIO DEL INTERIOR (2017). La estancia en prisión: Consecuencias y Reincidencia. Entidad Estatal Trabajo Penitenciario.

Secretaría General de Instituciones Penitenciarias. (2020). Datos estadísticos de la población reclusa. Madrid: Ministerio del Interior. Recuperado de https://www.institucionpenitenciaria.es/es/web/home/ vida-en-prision. 